\title{
Comparison of the morphology, antigenicity, and pathology of Nichols and Birmingham isolates of Treponema pallidum
}

\author{
C W PENN* AND J C CLAY†
}

From the *Department of Microbiology, University of Birmingham; and the + Special Clinic, Birmingham General Hospital, Birmingham

SUMMARY A strain of Treponema pallidum isolated from a homosexually acquired penile chancre in Birmingham in 1979. was serially passaged in rabbits and compared with the Nichols strain. The two strains appeared identical morphologically, and no gross differences were detected on antigenic analysis by two-dimensional immunoelectrophoresis. The Birmingham strain was, however, considerably less virulent for rabbits; the number of organisms required for equivalent time of development and severity of skin lesions was 10 -fold to 100 -fold greater for the Birmingham than for the Nichols strain. The pathology of testicular infection was broadly similar for both strains.

\section{Introduction}

The Nichols pathogenic strain of Treponema pallidum was originally isolated in $1913^{1}$ but has been used in about $90 \%$ of laboratory studies of pathogenic treponemes. ${ }^{2}$ It is also probably exclusively used as a source of antigen for treponemal immunodiagnostic tests for syphilis. It is therefore very important that the strain should be typical, both pathogenically and antigenically, of strains currently circulating in the infected human population.

Previous comparisons between the Nichols and other strains have been either immunological, showing that infection of rabbits gave differential protection against several challenge strains, ${ }^{2}{ }^{3}$ or genetic, showing that there were no gross differences in DNA composition between Nichols $T$ pallidum and $T$ pertenue. ${ }^{4}$ While differences in pathogenesis in animals between $T$ pallidum, $T$ carateum, and $T$ pertenue have been described $^{2}$ little comparison between strains of $T$ pallidum appears to have been reported, although heterogeneity such as the existence of "neurotropic" strains has been described in much earlier reports. ${ }^{5}$ Until recently ${ }^{6-8}$ little antigenic analysis of $T$ pallidum had been undertaken and no comparison of different isolates published.

Address for reprints: Dr C W Penn, Department of Microbiology, University of Birmingham, P O Box 363, Birmingham B15 2TT

Accepted for publication 11 May 1982
The isolation of a strain of $T$ pallidum in Birmingham, and its propagation in rabbits, has made possible the comparison of its morphology, pathology, virulence, and antigenic composition with that of the Nichols strain.

\section{Materials and methods}

STRAINS OF T PALLIDUM

The Nichols strain of $T$ pallidum was obtained, stored, and propagated in rabbits as described. ${ }^{9}$ The Birmingham strain was obtained from fluid expressed from a homosexually acquired primary penile chancre on a patient at the special clinic, Birmingham General Hospital, in November 1979. The specimen was diluted in $1 \mathrm{ml}$ of Nelson and Diesendruck's medium ${ }^{10}$ containing $15 \%(\mathrm{v} / \mathrm{v})$ glycerol, and stored frozen at $70^{\circ} \mathrm{C}$. The specimen $D$ was thawed when needed at $35^{\circ} \mathrm{C}$ and injected intratesticularly into a $3 \mathrm{~kg}$ Californian rabbit. $N$ Rabbits had been fed on an antibiotic-free diet. When maximal orchitis (with either strain) had developed, rabbits were killed by intravenous $\omega$ injection of pentobarbitone and the treponemes $\widetilde{\sigma}$ extracted from the testes. ${ }^{9}$ For serial passage of the 0 Birmingham strain $1 \mathrm{ml}$ of the suspension obtained $\bar{D}$ (containing $10^{6}-10^{8}$ treponemes $/ \mathrm{ml}$, depending on yield obtained from each rabbit) was injected undiluted into each testis of a further rabbit within one hour of the death of the donor rabbit. Infected rabbits (either strain) were treated initially with 
betamethasone $(0.05 \mathrm{mg} / \mathrm{kg}$ daily), but this was discontinued if orchitis had not developed by 30 days after infection.

\section{ELECTRON MICROSCOPY}

Treponemes were negatively stained ${ }^{8}$ and testicular tissue from infected rabbits fixed, processed, and sectioned for electron microscopy. ${ }^{9}$

\section{SEROLOGICAL ANALYSIS}

Antisera were obtained from rabbits infected for 2-3 months with either Nichols or Birmingham strains and selected for maximal immunoprecipitating activity. Antigenic extracts were prepared from the Nichols strain, both by ultrasonication and by extraction with Triton $\mathrm{X}-100 .^{8}$ Serological comparisons were made by causing antisera to both strains to react with the Nichols strain antigens by two-dimensional immunoelectrophoresis.

\section{ASSESSMENT OF VIRULENCE}

Rabbits were infected intratesticularly with similar doses of either the Nichols or Birmingham strains at such times that peak orchitis for both strains coincided on the same day. Treponemes were extracted ${ }^{8}$ and counted visually in a Thoma counting chamber by phase contrast with a $\times 40$ objective ( 32 or $48 \times 1 / 400 \mathrm{~mm}^{2}$ divisions, total $200-500$ treponemes); within 30 minutes of the death of the donor animal serial dilutions (containing equal numbers of the two strains) of the treponeme suspensions in the medium used for harvesting treponemes ${ }^{8}$ were injected intradermally into the shaved backs of two rabbits. The whole prodedure was performed a second time with fresh treponeme suspensions.

\section{Results}

IDENTIFICATION OF BIRMINGHAM ISOLATE Clinical findings and history, both in the patient and his previous sexual contact, confirmed a diagnosis of primary syphilis. The patient was a 44-year-old male homosexual with no previous history of sexually transmitted infection who presented with a four-dayold penile lesion. There was a painless indurated ulcer $5 \mathrm{~mm}$ in diameter on the coronal sulcus of the penis but no accompanying lymphadenopathy, rashes, or mucosal lesions. Darkground microscopial examination showed $T$ pallidum. The $T$ pallidum haemagglutination assay (TPHA), fluorescent treponemal antibody (FTA) test and Reiter protein complement-fixation test (RPCFT) gave positive results; the Venereal Disease Research Laboratory (VDRL) test was weakly reactive and the cardiolipin Wassermann reaction (CWR) negative. After treatment satisfactory serial reversal of test results occurred and eight months later only the FTA test result remained positive.

The source contact, who was seen later, had undoubted secondary syphilis with papular syphilide darkground-positive condylomata lata and strongly positive serological results (TPHA, FTA, and RPCFT, positive; VDRL, positive 1/64; CWR, positive $1 / 160$ ). After treatment satisfactory serial reversal of test results occurred and 10 months later, while diagnostic test results remained positive, the VDRL test was only weakly reactive and the CWR negative.

In addition organisms of the Birmingham strain were examined by the FTA-ABS test at the syphilis reference laboratory, Wolverhampton Royal Hospital. The Birmingham strain was used as antigen in parallel with the Nichols strain in tests for reaction with a series of sera from 40 patients with syphilis for total immunoglobulin as well as IgG and IgM. Identical results were obtained with both strains.

\section{MORPHOLOGY OF STRAINS}

The two strains appeared identical morphologically and in size by negative staining and electron microscopy (fig 1). In both cases, while most of the organisms possessed three axial filaments originating from each end about $10 \%$ of the organisms possessed four axial filaments at one or both ends, as shown in fig 1 .

\section{SEROLOGICAL COMPARISON}

Sera from rabbits infected with either strain were broadly similar in precipitating activity shown by two-dimensional immunoelectrophoresis against antigens from the Nichols strain (fig 2); four major immunoprecipitates including those labelled A and B were produced by the Birmingham strain antiserum. The most potent Birmingham strain sera were, however, less potent than the Nichols strain sera used, and one or two minor immunoprecipitates detected with the Nichols strain antisera were absent with Birmingham strain sera. Attempts to extract antigens from the Birmingham strain appeared to yield less antigen than was obtainable from the Nichols strain, although, because the numbers of Birmingham strain treponemes obtained were usually lower, volumes extracted were extremely small and losses may have occurred. Insufficient antigen was obtained for analysis by reciprocal two-dimensional immunoelectrophoresis.

\section{VIRULENCE}

Rabbits were examined daily and erythema, induration, haemorrhage, and ulceration at the site of injection noted. By all these criteria the Nichols 



FIG 1 Morphology of (a) Nichols and (b) Birmingham strains of T pallidum. Note the presence of four axial filaments on both specimens. Negative stain, electron micrograph. (Bars represent $0.5 \mu$ ).

strain appeared 10-fold to 100 -fold more virulent than the Birmingham strain. For brevity, only the number of days until first detection of induration (palpable with the finger tip) is given (table I). A photograph of lesions produced at 15 days (fig 3 ) illustrates these differences.

Duration of infection (incubation period) before maximal orchitis in intratesticularly infected rabbits also indicated differences in virulence between the strains. Table II shows that the incubation period for the Birmingham strain decreased on serial passage but stabilised after 4-5 passages at 20-35 days compared with an average of 10-12 days for the Nichols strain. The incubation period was not simply dependent on the infecting dose, since even good $\left(1 \times 10^{8} / \mathrm{ml}\right)$ batches of the Birmingham strain required longer incubation periods than poor $\left(1-5 \times 10^{7} / \mathrm{ml}\right)$ batches of the Nichols strain.. On average, yields of the Birmingham strain were approximately two-fold to five-fold lower than the usual $1-5 \times 10^{8} / \mathrm{ml}$ of the Nichols strain.

\section{PATHOLOGY}

As observed previously for the Nichols strain, ${ }^{9}$ testicular infection with the Birmingham strain was confined to interstitial tissues, and the vast majority of organisms were extracellular. Testicular infection with the Birmingham strain often appeared more
TABLE I Time of development of induration after intradermal injection into rabbits of Nichols and Birmingham strains of Treponema pallidum

\begin{tabular}{|c|c|c|c|}
\hline & \multirow[b]{2}{*}{$\begin{array}{l}\text { No of treponemes } \\
\text { injected }\end{array}$} & \multicolumn{2}{|c|}{$\begin{array}{l}\text { Days after injection to firs } \\
\text { detectable induration with }\end{array}$} \\
\hline & & $\begin{array}{l}\text { Nichols } \\
\text { strain }\end{array}$ & $\begin{array}{l}\text { Birmingham } \\
\text { strain }\end{array}$ \\
\hline $\begin{array}{l}\text { Experiment } 1: \\
\text { Rabbit No } 1\end{array}$ & $\begin{array}{l}10^{6} \\
10^{5} \\
10^{4} \\
10^{3}\end{array}$ & $\begin{array}{l}4 \\
5 \\
7 \\
\mathrm{NI}\end{array}$ & $\begin{array}{l}5 \\
8 \\
\text { NI } \\
\text { NI }\end{array}$ \\
\hline Rabbit No 2 & $\begin{array}{l}10^{6} \\
10^{5} \\
10^{4} \\
10^{3}\end{array}$ & $\begin{array}{l}4 \\
5 \\
7 \\
8\end{array}$ & $\begin{array}{l}5 \\
8 \\
\text { NI } \\
\text { NI }\end{array}$ \\
\hline $\begin{array}{l}\text { Experiment } 2: \\
\text { Rabbit No } 3\end{array}$ & $\begin{array}{l}5 \times 10^{6} \\
5 \times 10^{5} \\
5 \times 10^{4} \\
5 \times 10^{3}\end{array}$ & $\begin{array}{l}5 \\
6 \\
\text { NI } \\
\text { NI }\end{array}$ & $\begin{array}{l}\text { NI } \\
\text { NI } \\
\text { NI } \\
\text { NI }\end{array}$ \\
\hline Rabbit No 4 & $\begin{array}{l}5 \times 10^{6} \\
5 \times 10^{5} \\
5 \times 10^{4} \\
5 \times 10^{3}\end{array}$ & $\begin{array}{l}5 \\
5 \\
5 \\
6\end{array}$ & $\begin{array}{l}5 \\
6 \\
\text { NI } \\
\text { NI }\end{array}$ \\
\hline
\end{tabular}

$\mathrm{NI}=$ no induration observed up to 20 days after injection 


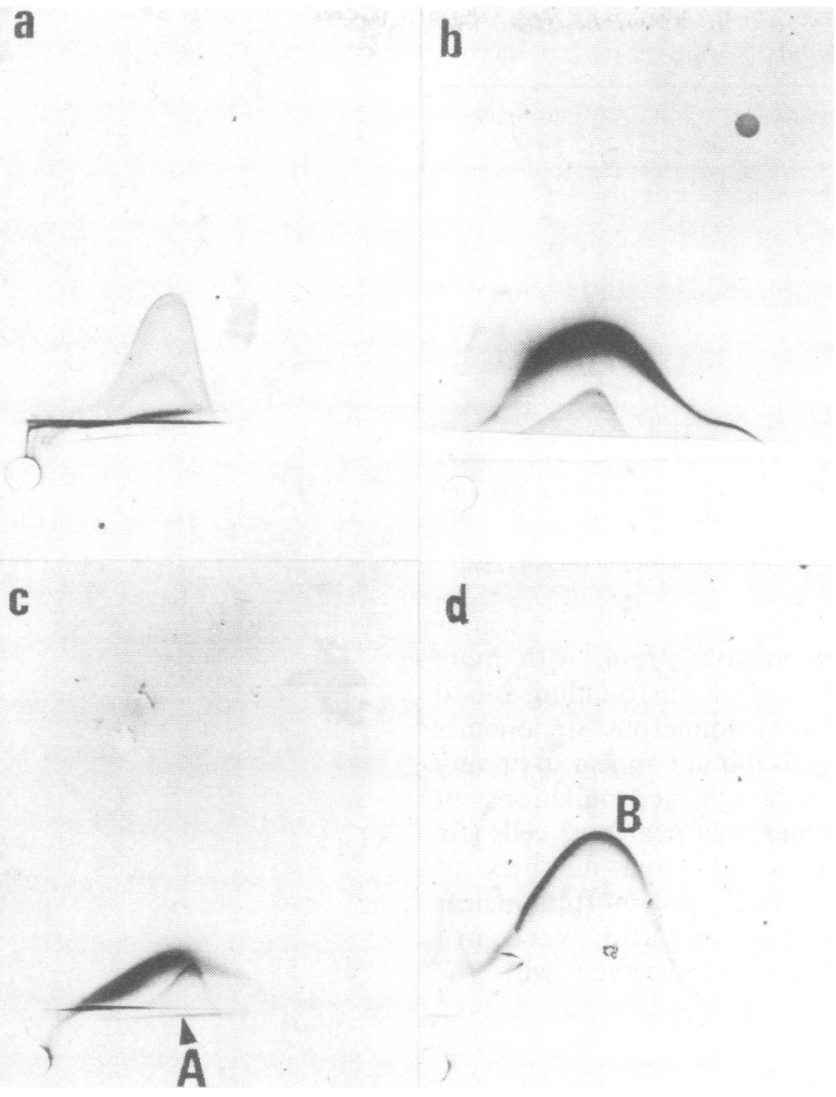

FIG 2 Two-dimensional immunoelectrophoresis patterns obtained with antigen (in wells) from sonicated ( $a$ and $c$ ) and Triton $X-100$-solubilised ( $b$ and d) $T$ pallidum (Nichols). Antisera (in upper gels) were from rabbits infected with Nichols ( $a$ and $b$ ) and Birmingham (c and d) strains. Anodes were to the right (first dimension) and top (second dimension).

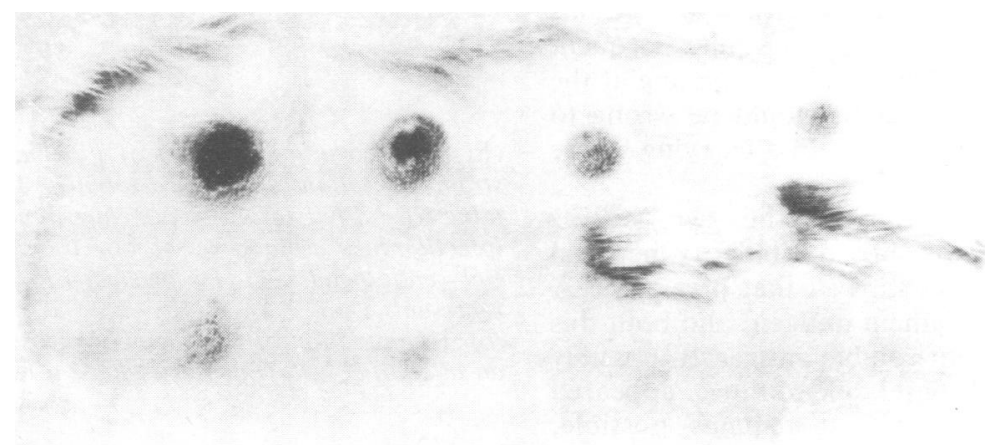

FIG 3 Lesions on the clipped dorsal skin of a rabbit 15 days after injection intradermally with graded doses of Nichols (top row) and Birmingham strains of $T$ pallidum, ranging from $5 \times 10^{6}$ (left) to $5 \times 10^{3}$ treponemes in a volume of $0.1 \mathrm{ml}$. 
TABLE II Passage history of Birmingham strain of Treponema pallidum in rabbits

\begin{tabular}{lll}
\hline Passage No & $\begin{array}{l}\text { Days to peak } \\
\text { orchitis }\end{array}$ & $\begin{array}{l}\text { Estimated } \\
\text { yield }\end{array}$ \\
\hline 1 & 180 & + \\
2 & 39 & ++ \\
3 & 30 & + \\
4 & 25 & ++ \\
5 & 20 & +++ \\
6 & 23 & + \\
7 & 26 & ++ \\
8 & 44 & ++ \\
$9 \dagger$ & 27 & ++ \\
$10 t$ & 29 & ++ \\
11 & 29 & +++ \\
\hline
\end{tabular}

*Estimated from visual counts of treponemes $/ \mathrm{ml}$ in the first extraction $(30 \mathrm{~min})$ from testes $\left(+=10^{6}-10^{7} ;++=10^{7}-10^{8}\right.$; $+++=>10^{8}$

†Batches used for comparison of virulence with the Nichols strain

localised than with the Nichols strain, with more intense foci of infection, often surrounding blood vessels and containing very numerous treponemes (fig 4a). Attachment to cells did not appear to be very pronounced in vivo, although accumulations of treponemes were sometimes seen near host cells (fig 4b). Despite the presence of large numbers of organisms near blood vessels, polymorphonuclear phagocytes were uncommon and were not phagocytosing treponemes, as observed with the Nichols strain. ${ }^{9}$

\section{Discussion}

Identification of a non-cultivable bacterium such as $T$ pallidum is heavily dependent on clinical diagnosis, which in this case was unequivocal and was confirmed independently by serological reactivity of the organisms by a standard FTA-ABS test.

The identical morphology of the two strains requires little comment, but the quite frequent occurrence of four axial filaments originating at the treponemal tip suggests that it would be wrong to define $T$ pallidum as invariably carrying three filaments. ${ }^{11}$

Serological comparisons of the two strains indicated that there was broad similarity between them. A previous study ${ }^{8}$ showed that precipitate A was formed by axial filament antigen, and both this and the major detergent-soluble antigen $B$, possibly associated with the outer membrane, appeared similar in the two strains. It remains possible, however, that there may be finer differences, which will not be detectable until larger quantities of antigen are obtained from the Birmingham strain for direct comparison. The Nichols strain was decidely more virulent for the rabbit than the Birmingham strain, but this may be due to superior adaptation of

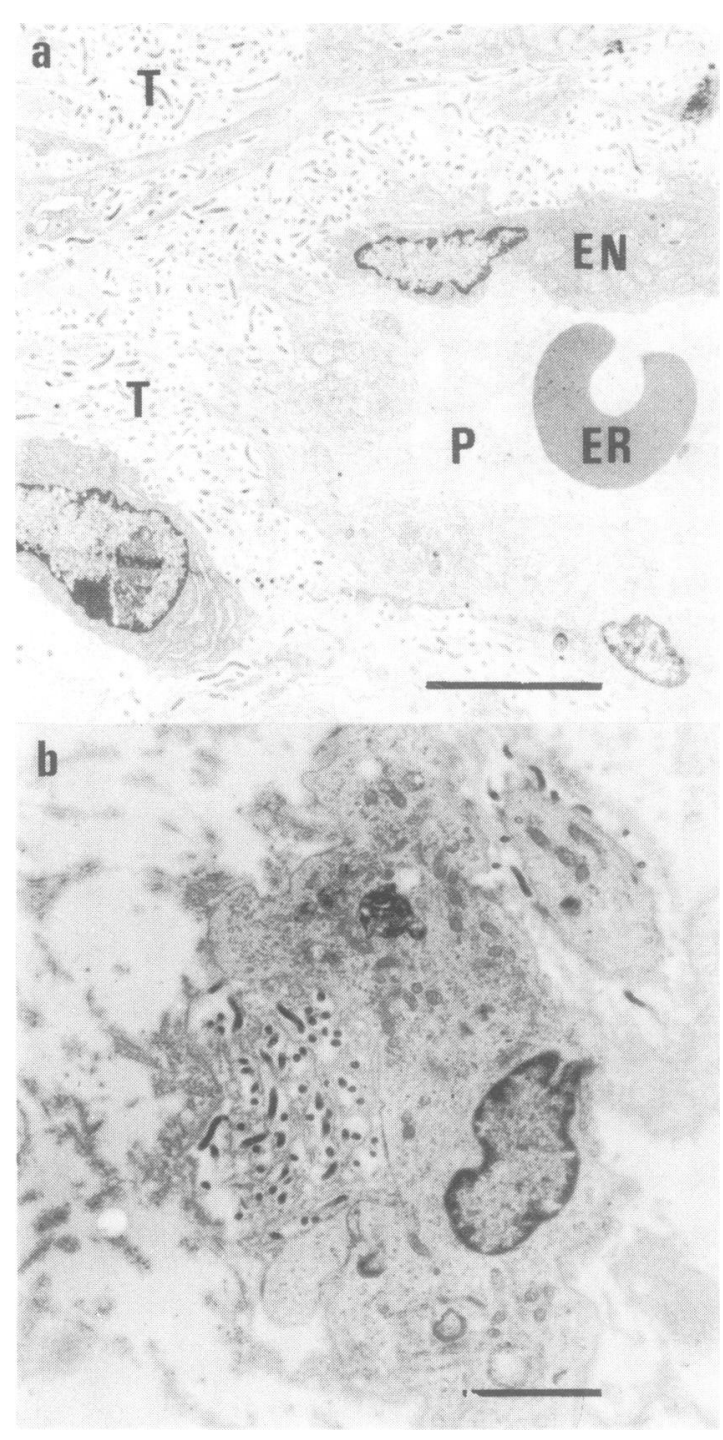

FIG 4 Electron micrographs of $T$ pallidum (Birmingham strain) in sections of infected rabbit testis (passage 5, table II). (a) Numerous treponemes in a focus of infection near a blood vessel. $(T=$ treponemes; $E N=$ endothelial cells; $P=$ plasma; $E R=$ erythrocyte; bar represents $5 \mu$.)

(b) Accumulation of treponemes in close association with an interstitial cell. (Bar represents $2 \mu$.)

the Nichols strain to growth in the rabbit. Since testicular passage routinely comprises inoculation of at least $1 \times 10^{7}$ treponemes, which then undergo only about 10-20 divisions per passage (assuming a generation time of about 30 hours $^{3}$ ), many passages-or reduced inocula and longer incubation 
periods-would be necessary to allow variants of progressively enhanced virulence to become predominant in the population. Without further serial passage of the Birmingham strain, however, the difference in virulence appears great enough to be useful in comparative studies for the identification of virulence factors of the organism. ${ }^{12}$

Despite the difference in time-scale of development of orchitis with the two strains, the testicular pathology appeared quite similar and suggested that the stimulus for triggering enlargement and induration was an accumulation of sufficient numbers of treponemes rather than, for example, the maturation of an immune response.

Previous work with the Nichols strain ${ }^{9}$ showed that polymorphonuclear leucocyte infiltration was absent both with and without betamethasone treatment. The absence of such infiltration in infection with the Birmingham strain could not therefore be attributed to betamethasone treatment.

The broad antigenic and pathological similarity between the strains suggests that the Nichols strain remains a useful subject for research into the pathogenicity of $T$ pallidum.

The laboratory work was supported by the Wellcome Trust. We are grateful to the staff of the VD Department, Birmingham General Hospital, for assistance with isolation of the Birmingham strain; to J Rhodes, J Lichfield, and D Ruffles for technical assistance; and to D Cox for performing the FTAABS tests.

\section{References}

1. Nichols HJ, Hough WH. Demonstration of Spirochaeta pallida in the cerebrospinal fluid from a patient with nervous relapse following the use of salvarsan. JAMA 1913;60:108-10.

2. Hardy PH. Pathogenic treponemes. In: Johnson RC, ed. The Biology of Parasitic Spirochetes. New York: Academic Press 1979; $107-19$.

3. Turner TB, Hollander DH. Biology of the Treponematoses, Monograph Series No 35. Geneva: WHO, 1957.

4. Miao RM, Fieldsteel AH. Genetic relationships between Treponema pallidum and Treponema pertenue; two noncultivable human pathogens. $J$ Bacteriol 1980;141:427-9.

5. Stokes $\mathrm{JH}$, Beerman $\mathrm{H}$, Ingraham NR. Modern Clinical Syphilology. Philadelphia: Saunders, 1944;968-9.

6. Strandberg-Pedersen N, Axelsen NH, J $\phi$ rgensen BB, SandPetersen C. Antibodies in secondary syphilis against five of forty Reiter treponeme antigens. Scand J Immunol 1980;11:629-33.

7. Strandberg-Pedersen N, Axelsen NH, Sand-Petersen C. Antigenic analysis of Treponema pallidum: cross-reactions between individual antigens of Treponema pallidum and Treponema Reiter. Scand J Immunol 1981;13:143-50.

8. Penn CW, Rhodes J. Surface-associated antigens of Treponema pallidum concealed by an inert outer layer. Immunology 1982;46:9-16.

9. Penn CW. Avoidance of host defences by Treponema pallidum in situ and on extraction from infected rabbit testes. $J$ Gen Microbiol 1981;126:69-75.

10. Nelson RA, Diesendruck JA. Studies on treponemal immobilizing antibodies in syphilis. J Immunol 1951;66:667-85.

11. Hovind-Hougen K. Treponema and Borrelia morphology. In: Johnson RC, ed. The Biology of Parasitic Spirochetes. New York: Academic Press, 1976: 7-18.

12. Smith $\mathbf{H}$. The determinants of microbial pathogenicity in relation to spirochetal disease. In: Johnson RC, ed. The Biology of Parasitic Spirochetes. New York: Academic Press, 1976:235-47. 